\title{
The risk of hypotension following co-prescription of macrolide antibiotics and calcium-channel blockers
}

\author{
Alissa J. Wright MD, Tara Gomes MHSc, Muhammad M. Mamdani PharmD MPH, John R. Horn PharmD, \\ David N. Juurlink MD PhD
}

\begin{abstract}
Background: The macrolide antibiotics clarithromycin and erythromycin may potentiate calcium-channel blockers by inhibiting cytochrome P450 isoenzyme 3A4. However, this potential drug interaction is widely underappreciated and its clinical consequences have not been well characterized. We explored the risk of hypotension or shock requiring hospital admission following the simultaneous use of calcium-channel blockers and macrolide antibiotics.
\end{abstract}

Methods: We conducted a population-based, nested, case-crossover study involving people aged 66 years and older who had been prescribed a calcium-channel blocker between Apr. 1, 1994, and Mar. 31, 2009. Of these patients, we included those who had been admitted to hospital for the treatment of hypotension or shock. For each antibiotic, we estimated the risk of hypotension or shock associated with the use of a calcium blocker using a pair-matched analytic approach to contrast each patient's exposure to each macrolide antibiotic (erythromycin, clarithromycin or azithromycin) in a seven-day risk interval immediately before admission to hos- pital and in a seven-day control interval one month earlier.

Results: Of the 7100 patients admitted to hospital because of hypotension while receiving a calcium-channel blocker, 176 had been prescribed a macrolide antibiotic during either the risk or control intervals. Erythromycin (the strongest inhibitor of cytochrome P450 3A4) was most strongly associated with hypotension (odds ratio [OR] 5.8, 95\% confidence interval [CI] 2.3-15.0), followed by clarithromycin (OR 3.7, 95\% Cl 2.3-6.1). Azithromycin, which does not inhibit cytochrome P450 3A4, was not associated with an increased risk of hypotension (OR $1.5,95 \% \mathrm{Cl} 0.8-2.8)$. We found similar results in a stratified analysis of patients who received only dihydropyridine calcium-channel blockers.

Interpretation: In older patients receiving a calcium-channel blocker, use of erythromycin or clarithromycin was associated with an increased risk of hypotension or shock requiring admission to hospital. Preferential use of azithromycin should be considered when a macrolide antibiotic is required for patients already receiving a calcium-channel blocker.

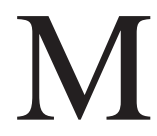

acrolides (erythromycin, clarithromycin and azithromycin) are the most widely prescribed antibiotics, with over 66 million prescriptions dispensed in 2008 in the United States alone. ${ }^{1}$ Although they are generally well tolerated, they can provoke drug interactions by several mechanisms. The most well-studied of these involves the inhibition of the cytochrome P450 enzymes involved in drug metabolism, particularly cytochrome P450 isoenzyme 3A4. This enzyme plays an important role in the metabolism of many medications. It is strongly inhibited by clarithromycin and erythromycin but not by azithromycin. ${ }^{2,3}$ In the presence of an inhibitor of this isoenzyme, drugs that require cytochrome P450 3A4 for their metabolism will accumulate, potentially leading to toxicity. 4,5

Cytochrome P450 3A4 has many substrates of clinical relevance, but the calcium-channel blockers are of particular importance. These drugs are widely used for several chronic conditions, including hypertension and coronary artery disease. They are the ninth most commonly prescribed class of medications in the United States, with almost 90 million prescriptions dispensed in 2008. ${ }^{1}$ Moreover, they are all substrates for cytochrome P450 3A4. ${ }^{6,7}$ Erythromycin was shown to increase felodipine levels by about $300 \%$ in 12 patients, ${ }^{8}$ and several case reports have described significant cardiovascular toxicity in patients receiving a calcium-channel blocker in combination with erythromycin or clarithromycin. ${ }^{9-13}$ In contrast, no reports describe
Competing interests:

Muhammad Mamdani has worked as a consultant for Pfizer, Novartis and JansenOrtho. John Horn has worked as a consultant for Merck Consumer Care, and is the author of several books on the subject of drug interactions. No competing interests were declared by the other authors.

This article has been peer reviewed.

Correspondence to:

Dr. David Juurlink,

dnj@ices.on.ca

CMAJ 2011. DOI:10.1503 /cmaj.100702 
such toxicity in patients given azithromycin, which is consistent with the observation that it does not inhibit cytochrome P450 3A4..$^{14}$

Given the popularity of macrolides and calcium-channel blockers, millions of patients worldwide are likely exposed to this drug combination each year. However, the potential interaction between these drugs is not widely appreciated, and no rigorous studies describe the clinical consequences. We analyzed the health care records of more than 1.5 million older individuals to characterize the clinical consequences of macrolide use among patients who were taking a calcium-channel blocker.

\section{Methods}

\section{Data sources}

We conducted a population-based study of residents aged 66 years or older in the province of Ontario. Prescription drug records were obtained from the Ontario Drug Benefit Claims Database, and information on hospital admissions was collected using the Canadian Institute for Health Information's Discharge Abstract Database. Demographic information was derived from the Registered Persons Database, which contains an entry for each resident of Ontario who has been issued a health card. Finally, the Ontario Health Insurance Plan Database provided information regarding claims for physician services. These databases are linked anonymously using encrypted health card numbers. They are routinely used to study drug safety, including the consequences of drug interactions. ${ }^{15-18}$ This study was approved by the Research Ethics Board of the Sunnybrook Health Sciences Centre.

\section{Identification of patients and outcomes}

We established a cohort of patients prescribed a single calcium-channel blocker (verapamil, diltiazem, nifedipine, amlodipine or felodipine) between Apr. 1, 1994, and Mar. 31, 2009. For each patient, we defined a period of continuous use of a calcium-channel blocker beginning with the first prescription for the drug after the patient's 66th birthday, as has been done in previous studies. ${ }^{15,16,18}$ Continuous use of calciumchannel blockers was defined as the receipt of a refill for the drug within 180 days of the date of the previous prescription. Patients were deemed to have stopped their therapy if more than 180 days elapsed between prescriptions. In this situation, patients were followed for an additional 60 days from the date of their last prescription to identify any events that may have precipitated cessation. Observation ended with admission to hospital for treatment of an out- come of interest, death, discontinuation of therapy or a switch to a different calcium-channel blocker, whichever occurred first.

We excluded patients during their first year of eligibility for coverage of prescription medications under the Ontario Drug Benefit Program (i.e., those aged 65 years) to avoid incomplete medication records. Patients who had prescriptions for more than one macrolide in the 30 days before admission to hospital were also excluded.

In the primary analysis, we identified patients in the cohort who were admitted to hospital for treatment of either hypotension or shock according to the following International Classification of Diseases codes (both the 9th and 10th revisions were used): ICD-9 458.0, 458.1, 458.9, 785.50, 785.51 and 785.59; and ICD-10 I95.0, I95.1, I95.2, I95.8, I95.9, R57.0, R57.1, R57.8 and R57.9. We examined data only for patients in whom hypotension was present at the time of admission to hospital. The date of admission to hospital served as the reference date for all analyses. Only the first instance of each outcome was examined for each patient.

\section{Design and analysis}

We used the case-crossover design to avoid potential concerns about unresolved confounding. This technique allows one to assess the brief change in risk associated with a transient exposure. ${ }^{19}$ Under this design, each person serves as his or her own control; consequently, confounding due to age, sex and other fixed patient factors is extinguished. We used the pair-matched analytic approach to contrast exposure to each macrolide in a seven-day risk period immediately before admission to hospital with a seven-day control period one month earlier. The case-crossover design was nested in the cohort of patients receiving a calcium-channel blocker.

For each of the macrolide antibiotics, we estimated the risk of hypotension during treatment with a calcium-channel blocker based on the odds ratio, contrasting exposure during the risk period against exposure during the control interval. The possible role of chance was assessed using the McNemar test. The threshold for statistical significance was set at a two-tailed type I error rate of 0.05 .

\section{Results}

We identified 999234 patients who were receiving a single calcium-channel blocker during the period under investigation. The median age was 71 years (interquartile range [IQR] 67-78 years). Within this cohort, 7100 patients were admitted to hospital for the treatment of hypotension (Table 1). Slightly more than half of these patients were 
women, the median age was 77 years (IQR 72-83) and 176 patients had received a macrolide during either the risk or control intervals.

We found a strong association between erythromycin use and admission to hospital for the treatment of hypotension (odds ratio [OR] 5.8, 95\% confidence interval $[\mathrm{CI}] 2.3-15.0$ ), along with a marginally lower but significant risk associated with the use of clarithromycin (OR 3.7, 95\% CI 2.3-6.1; Table 2). In contrast, we found no such association with azithromycin use (OR $1.5,95 \%$ CI $0.8-2.8)$. We found similar results in a stratified analysis of patients receiving one of the dihydropyridine calcium-channel blockers (nifedipine, amlodipine or felodipine; Table 3).

\section{Interpretation}

Among older patients receiving calcium-channel blockers, the use of erythromycin and clar- ithromycin was associated with a markedly increased short-term risk of admission to hospital, whereas azithromycin use was not. These findings are consistent with previous case reports and with the known pharmacology of these drugs (erythromycin and clarithromycin both inhibit cytochrome P450 3A4, whereas azithromycin does not). They therefore have considerable clinical relevance. Calcium-channel blockers and macrolide antibiotics are among the most widely prescribed medications in Canada, and their interactions are both dangerous and greatly underappreciated. When a macrolide antibiotic is necessary, the interaction is easily avoided if azithromycin is given to patients who are already receiving a calcium-channel blocker.

\section{Limitations}

Several limitations of this study merit emphasis. We were unable to quantify medication adher-

\begin{tabular}{|c|c|c|c|}
\hline Variable & $\begin{array}{c}\text { No. (\%) of patients* } \\
n=7100\end{array}$ & Variable & $\begin{array}{c}\text { No. }(\%) \text { of patients* } \\
n=7100\end{array}$ \\
\hline Age, yr, median (IQR) & $77(72-83)$ & Myocardial infarction in the last 2 years & $1169(16.5)$ \\
\hline $65-74$ & $2631(37.1)$ & Heart failure in the last 2 years & $1208(17.0)$ \\
\hline $75-84$ & $3057(43.1)$ & Medication use in the last 100 days & \\
\hline$\geq 85$ & $1412(19.9)$ & P-glycoprotein inhibitorst & $4762(67.1)$ \\
\hline No. of years using a CCB, median (IQR) & $2(1-5)$ & ACE inhibitor & $3256(45.9)$ \\
\hline Type of CCB & & NSAID & $2724(38.4)$ \\
\hline Diltiazem & $2838(40.0)$ & Other diuretic & $2547(35.9)$ \\
\hline Verapamil & $566(8.0)$ & $\beta$-adrenergic antagonist & $2510(35.4)$ \\
\hline Nifedipine & $1379(19.4)$ & Statin & $2182(30.7)$ \\
\hline Amlodipine & $2101(29.6)$ & Thiazide & $1371(19.3)$ \\
\hline Felodipine & 216 (3.0) & Digoxin & $1117(15.7)$ \\
\hline Sex, male & $3349(47.2)$ & CYP3A4 inhibitorsł & $886(12.5)$ \\
\hline Resident in long-term care facility & $212(3.0)$ & CYP3A4 inducers§ & $201(2.8)$ \\
\hline Income quintile & & Angiotensin receptor blocker & $696(9.8)$ \\
\hline Missing data & $132(1.9)$ & Spironolactone & $399(5.6)$ \\
\hline 1 (lowest) & $1685(23.7)$ & Charlson Comorbidity Index & \\
\hline 2 & $1618(22.8)$ & 0 & $1210(17.0)$ \\
\hline 3 & $1304(18.4)$ & 1 & $1240(17.5)$ \\
\hline 4 & $1195(16.8)$ & $\geq 2$ & $2928(41.2)$ \\
\hline 5 (highest) & $1166(16.4)$ & No admission to hospital & $1722(24.3)$ \\
\hline $\begin{array}{l}\text { No. of admissions to hospital in the } \\
\text { last year, median (IQR) }\end{array}$ & $0(0-1)$ & Renal disease in the last year & $562(7.9)$ \\
\hline $\begin{array}{l}\text { No. of medications prescribed in the } \\
\text { last } 100 \text { days, median (IQR) }\end{array}$ & $12(9-17)$ & & \\
\hline \multicolumn{4}{|c|}{$\begin{array}{l}\text { Note: } \mathrm{ACE}=\text { angiotensin converting enzyme, CCB = calcium-channel blocker, CYP3A4 = cytochrome P450 isoenzyme 3A4, IQR = interquartile range, NSAID = nonsteroidal anti- } \\
\text { inflammatory drug. } \\
\text { *Unless otherwise stated. } \\
\text { †Amiodarone, atorvastatin, carvedilol, itraconazole, nelfinavir, ritonavir and saquinavir. } \\
\text { †Amiodarone, aprepitant, ciprofloxacin, delavirdine, fluconazole, imatinib, indinavir, itraconazole, nefazodone, nelfinavir, norfloxacin, ritonavir, saquinavir, telithromycin and } \\
\text { voriconazole. } \\
\text { §Carbamazepine, efavirenz, nevirapine, phenobarbital, phenytoin and pioglitazone. }\end{array}$} \\
\hline
\end{tabular}


Table 2: Odds of admission to hospital for the treatment of hypotension or shock associated with recent exposure to macrolide antibiotics among patients already taking a calcium-channel blocker*

\begin{tabular}{|lcccc|}
\hline Antibiotic & $\begin{array}{c}\text { Use during risk } \\
\text { interval }\end{array}$ & $\begin{array}{c}\text { Use during control } \\
\text { interval }\end{array}$ & $p$ value & OR (95\% Cl) \\
\hline Erythromycin & 30 & 6 & $<0.001$ & $5.80(2.25-14.98)$ \\
\hline Clarithromycin & 77 & 23 & $<0.001$ & $3.70(2.26-6.06)$ \\
\hline Azithromycin & 24 & 16 & 0.21 & $1.50(0.8-2.82)$ \\
\hline
\end{tabular}

Note: $\mathrm{Cl}=$ confidence interval, $\mathrm{OR}=$ odds ratio.

*Risk interval = seven days before hospital admission; control interval = seven-day period one month before admission

Table 3: Odds of admission to hospital for the treatment of hypotension or shock and use of macrolide antibiotics among patients receiving a dihydropryidine calcium-channel blocker*

\begin{tabular}{|lcccc|}
\hline Antibiotic & $\begin{array}{c}\text { Use during risk } \\
\text { interval }\end{array}$ & $\begin{array}{c}\text { Use during control } \\
\text { interval }\end{array}$ & $p$ value & OR $(95 \% \mathrm{Cl})$ \\
\hline Erythromycin & 17 & $\leq 5 \dagger$ & 0.01 & $3.40(1.25-2.78)$ \\
\hline Clarithromycin & 51 & 12 & $<0.001$ & $4.25(2.23-7.97)$ \\
\hline Azithromycin & 12 & 10 & 0.67 & $1.20(0.52-2.78)$ \\
\hline $\begin{array}{l}\text { Note: } \mathrm{Cl}=\text { confidence interval, OR }=\text { odds ratio. } \\
* \text { Nifedipine, felodipine or amllodipine. } \\
\text { tCells with five or fewer observations are suppressed in accordance with institutional privacy policy. }\end{array}$ & \\
\hline
\end{tabular}

ence, or type and severity of infection, and the accuracy of diagnostic codes for hypotension has not been validated. Hypotension has multiple possible causes, and some instances of hypotension may have reflected the response to infection rather than the consequence of a drug interaction. We did not have sufficient statistical power to explore the outcome of bradycardia, which, along with hypotension, might be expected in patients receiving verapamil or diltiazem. Finally, we were unable to characterize the magnitude of interaction for each of the calciumchannel blockers. This is important because the inhibitory effect of erythromycin and clarithromycin on cytochrome P450 3A4 would be expected to result in a greater relative increase in the level of calcium-channel blockers that undergo greater presystemic elimination, most notably felodipine. ${ }^{20}$ However, these limitations apply equally to all macrolide antibiotics, including azithromycin, the inclusion of which lessens the role of confounding in our analyses. These limitations are unlikely to explain the differential risk seen with clarithromycin and erythromycin, which is biologically plausible and predicted by the pharmacology of these drugs.

\section{Conclusion}

We found that older patients taking a calciumchannel blocker were at increased risk of admission to hospital for the treatment of hypotension or shock following the use of clarithromycin or ery- thromycin. Our findings highlight the consequences of an underappreciated yet avoidable drug interaction involving medications used by millions of patients every year. Clinicians should be aware of the potential interaction between these drugs. When a macrolide is required, preferential use of azithromycin should be considered in patients already receiving a calcium-channel blocker.

\section{References}

1. IMS Health. Top therapeutic classes by dispensed prescriptions. Thetford Center (VT): MarketingCharts. Available: www marketingcharts.com/topics/us-prescription-drug-sales-grow -slowly-hydrocodone-most-prescribed-8462/ims-top-15-us -therapeutic-classes-dispensed-prescriptions-2008jpg/ (accessed 2009 July 1).

2. Periti P, Mazzei T, Mini E, et al. Pharmacokinetic drug interactions of macrolides. Clin Pharmacokinet 1992;23:106-31.

3. Westphal JF. Macrolide-induced clinically relevant drug interactions with cytochrome P-450A (CYP) 3A4: an update focused on clarithromycin, azithromycin and dirithromycin. Br J Clin Pharmacol 2000;50:285-95.

4. Dresser GK, Spence JD, Bailey DG. Pharmacokinetic-pharmacodynamic consequences and clinical relevance of cytochrome P450 3A4 inhibition. Clin Pharmacokinet 2000;38:41-57.

5. Zhou S, Chan E, Li X, et al. Clinical outcomes and management of mechanism-based inhibition of cytochrome P450 3A4. Ther Clin Risk Manag 2005;1:3-13.

6. Sica DA. Interaction of grapefruit juice and calcium channel blockers. Am J Hypertens 2006;19:768-73.

7. Dorne JL, Walton K, Renwick AG. Human variability in CYP3A4 metabolism and CYP3A4-related uncertainty factors for risk assessment. Food Chem Toxicol 2003;41:201-24.

8. Bailey DG, Bend JR, Arnold JM, et al. Erythromycin-felodipine interaction: magnitude, mechanism, and comparison with grapefruit juice. Clin Pharmacol Ther 1996;60:25-33.

9. Liedholm H, Nordin G. Erythromycin-felodipine interaction. DICP 1991;25:1007-8.

10. Kaeser YA, Brunner F, Drewe J, et al. Severe hypotension and bradycardia associated with verapamil and clarithromycin. Am J Health Syst Pharm 1998;55:2417-8. 
11. Steenbergen JA, Stauffer VL. Potential macrolide interaction with verapamil. Ann Pharmacother 1998;32:387-8.

12. Goldschmidt N, Azaz-Livshits T, Gotsman, et al. Compound cardiac toxicity of oral erythromycin and verapamil. Ann Pharmacother 2001;35:1396-9.

13. Geronimo-Pardo M, Cuartero-del-Pozo AB, Jimenez-Vizuete JM, et al. Clarithromycin-nifedipine interaction as possible cause of vasodilatory shock. Ann Pharmacother 2005;39:538-42.

14. Pai MP, Graci DM, Amsden GW. Macrolide drug interactions: an update. Ann Pharmacother 2000;34:495-513.

15. Juurlink DN, Mamdani M, Kopp A, et al. Drug-drug interactions among elderly patients hospitalized for drug toxicity. JAMA 2003;289:1652-8.

16. Park-Wyllie LY, Juurlink DN, Kopp A, et al. Outpatient gatifloxacin therapy and dysglycemia in older adults. $N$ Engl J Med 2006:354:1352-61.

17. Juurlink DN, Gomes T, Ko DT, et al. A population-based study of the drug interaction between proton pump inhibitors and clopidogrel. CMAJ 2009;180:713-8.

18. Juurlink DN, Mamdani MM, Lee DS, et al. Rates of hyperkalemia after publication of the Randomized Aldactone Evaluation Study. N Engl J Med 2004;351:543-51.

19. Maclure M. The case-crossover design: a method for studying transient effects on the risk of acute events. Am J Epidemiol 1991; 133:144-53

20. Kirsten R, Nelson K, Kirsten D, et al. Clinical pharmacokinetics of vasodilators. Part I. Clin Pharmacokinet 1998;34:457-82.

Affiliations: From the Departments of Medicine (Wright, Juurlink) and Health Policy, Management and Evaluation (Mamdani), University of Toronto, Toronto, Ont.; St. Michael's Hospital, Applied Health Research Centre, Li Ka Shing Knowledge Institute (Mamdani), Toronto, Ont.; the Departments of Pharmacy and Pharmacy Services (Horn), University of Washington, Seattle, Wash.; the Sunnybrook Research Institute (Juurlink), Toronto, Ont.; and the Institute for Clinical Evaluative Sciences (Mamdani, Gomes, Juurlink), Toronto, Ont.

Contributors: David Juurlink is the study guarantor and assumes responsibility for the integrity of the data and the accuracy of the analysis. Alissa Wright, Tara Gomes, Muhammad Mamdani, John Horn and David Juurlink contributed to the concept and design of the study. Alissa Wright and David Juurlink drafted the manuscript. Tara Gomes performed the analyses. All of the authors contributed to the interpretation of the analysis, revised the manuscript and approved the version submitted for publication.

Funding: This study was supported by the Institute for Clinical Evaluative Sciences (ICES), which is funded by an annual grant from the Ontario Ministry of Health and LongTerm Care. The study was supported in part by the Ontario Drug Innovation Fund, which had no role in the design, analysis, conduct or reporting of the study. The opinions, results and conclusions reported in this paper are those of the authors and are independent from the funding sources. No endorsement by ICES or the Ontario Ministry of Health and Long-Term Care is intended or should be inferred.

Acknowledgements: The authors thank Brogan Inc., Ottawa, Ont., for use of its Drug Product and Therapeutic Class Database, and Ashif Kachra, Jill Tomac and Chelsea Hellings for assistance with manuscript preparation.

Presented in part at the Canadian Society of Internal Medicine Annual Scientific Meeting in Vancouver, British Columbia, Oct. 30, 2010.

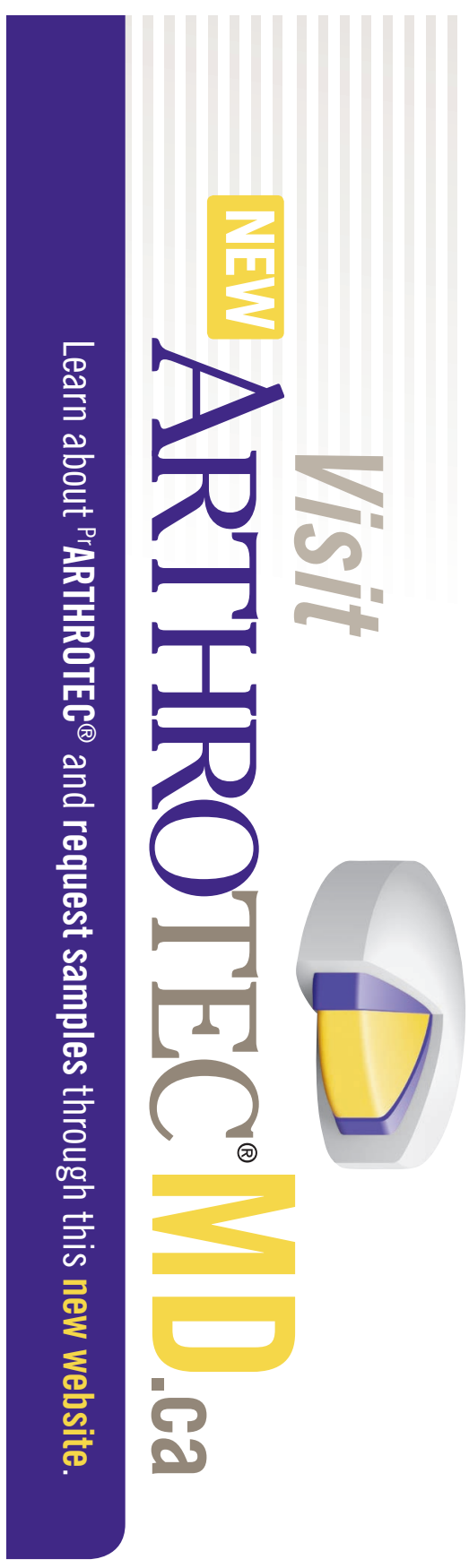

An NSAID with a mucosal protective agent, PrARTHROTEC ${ }^{\circledR}$ (50 \& $75 \mathrm{mg}$ diclofenac sodium and misoprostol tablets) has contraindications as well as warnings and precautions of use.

Please consult the Prescribing Information which is available on the ARTHROTECMD.ca website, or the Product Monograph which is available upon request.

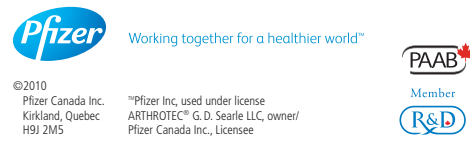

